\title{
A VOZ AFRICANA NA CULTURA BRASILEIRA E AS CULTURAS INVERSAS ENTRE BRASIL E ÁFRICA
}

\author{
João Carlos Gomes ${ }^{1}$ \\ jccgomes777@itelefonica.com.br
}

Este trabalho se inicia com uma perspectiva de elucidar os caminhos percorridos pelos negros no decorrer da história do Brasil, traçando um mapa da miscigenação, do sincretismo religioso, da língua, da condição social que foi colocada o povo negro.

O trabalho começa no período colonial e no momento da chegada dos africanos no Brasil, na formação das comunidades e seu acondicionamento, que fez dessa raça menosprezada e diminuída a amálgama de manipulação dos colonizadores, no desenvolvimento cultural que fez do negro um ser em condição de destaque.

Os olhares sociais que também estão presentes em um país cuja formação intelectual e a escrita era escassa como era a condição do continente africano, sendo que, outros sentidos foram desenvolvidos como foi a do povo africano que lutava pela libertação do seu país, na construção a sociedade libertadora, na construção da sua literatura e na afirmação como cidadão de sua terra e do mundo.

Os primeiros registros da construção da escrita do negro no Brasil e a catalogação do seu vocabulário como forma de expressar seus sentimentos e sua luta para a igualdade dos povos que se confluíam durante a colonização.

A literatura do período da República criou um modelo a ser seguido que ditou a regra no movimento realista brasileiro fazendo críticas e mostrando uma realidade até então escondida que vieram à tona com o desenvolver dessa escrita.

\footnotetext{
${ }^{1}$ Pós-graduando em Cultura Afro-brasileira nas Faculdades Integradas de Jacarepaguá e Instituto Signorelli de Pesquisa (Tema do TCC: O Brasil dos africanos - Da musicalidade à oralidade africana e as influências na cultura brasileira). Graduado em Letras pela Unipinhal com licenciatura plena em Português e Espanhol (Tema do TCC: África dos portugueses - Agostinho Neto).
} 
A música é uma das manifestações de maior expressividade da identificação da negritude na sua maneira única de ser mostrado com o auxílio de madeiras ocas, com o couro de animais mortos que fazem da música um momento de êxtase e alegria no compasso do ritmo que é frenético, fazendo com que o ser humano que está inerte se torne um coração pulsante no ritmar dos tambores.

O sincretismo religioso está presente nesta pesquisa para mostrar a forma de imposição elaborada pelos brasileiros que, de certa forma, impunham o catolicismo para os negros nos períodos de colonização. As formas implícitas utilizadas pelos negros para a manifestação religiosa, com a função de afirmação de seu povo, como é feita no candomblé que estava inserido em suas atribuições a confirmação da raça negra calcado em seus direitos de cidadão africano.

A língua também tem destaque neste trabalho, pois foi através dela que o homem branco pôde reconhecer nos negros uma cultura bastante elaborada em oralidade e musicalidade e sua importância diante do acondicionamento desta etnia tão sofrida e perseguida durante os tempos. As suas características ágrafas, as suas marcas deixadas na sociedade brasileira da época, o vocabulário extenso deixado como herança na cultura brasileira que persiste até hoje elevando a condição do homem negro como ser integrante do Brasil.

A condição social também é foco deste caminho a ser percorrido, pois a partir da formação dos povos negros no país como sociedade organizada a cortina de ferro foi descerrada para que uma nova história fosse escrita, isso faz com que a memória de um povo seja verdadeiramente exaltada e reconhecida para que os seus herdeiros possam desfrutar.

As condições sociais e desumanas de moradia e as formas como elas se apresentam mostram o ambiente que vivia o povo negro, atingindo assim de uma maneira direta a personalidade dos homens e mulheres que receberam das mãos da desigualdade brasileira as moradias alternativas chamadas de favelas que estão dispostas nos altos dos morros das grandes cidades, principalmente nos grandes centros urbanos com destaque São Paulo e Rio de Janeiro. 
A maneira como ela se apresenta para o mundo e o formato de sociedade que existe nestas favelas estão distantes de uma condição humana digna de se viver.

O Brasil negreiro será desmistificado na sua maneira mais profunda e a sua alma será liberta de tanta indiferença para mostrar através do trabalho uma nova cara, sendo que a negritude será mostrada em meio a sua cultura, que foram destaques dentro da música libertadora, da literatura e da arte.

A cultura afro-brasileira hoje aparece com uma estrutura firmada na história e na realidade contemporânea que lhe é peculiar, perfilados entre as grandes manifestações culturais do mundo, portanto essa cultura vem carregada de emoção e contentamento devido às origens e à excelência como foi elaborada.

A aceitação do negro como cidadão brasileiro está nas entrelinhas dos textos que serão estudados e farão frente às formas racistas destiladas na sociedade brasileira pela mídia e pelos modelos da modernidade que não corroboram na valorização da raça negra.

A literatura brasileira e a literatura africana têm um parentesco muito forte e são contundentes, porque mostram em sua estética os conflitos políticos e sociais vividos por ambos os povos e reforçam a luta na busca de um dia mais feliz. Libertas das indiferenças impostas nos anos de chumbo, as letras das músicas, os poemas, os contos tinham como fontes inspiradoras três vertentes: a vida, a luta e a esperança que eram as bandeiras que tremulavam em meio às manifestações nacionalistas.

Os heróis serão lembrados e citados para que os futuros estudantes possam se firmar em uma história verdadeira e consistente para elaborar uma leitura crítica influenciada por uma raça cheia de experiências.

A história será colocada nas frequentes inserções feitas nos livros de pesquisa que foram elaborados a partir de um rigoroso estudo detalhado e condicionado na adversidade contando com toda a frequência de pensamentos que, quando diluídos, são de grande valia para a humanidade. 
Os problemas serão descritos para que as novas gerações entendam como foi difícil desbravar essa mata fechada de preconceitos e indiferenças, mas com um fio de esperança construído em um dilema constante de aceitação a sua realidade.

Caminhos novos e distintos serão exibidos para que seja deixado registrado aos homens que sem uma fórmula de intensa formação intelectual e objetividade o negro não sairá da senzala que o prende, somente deixará de ser ele mesmo para viver um personagem, uma marionete.

O perfil psicológico do jovem negro é uma incógnita porque a sociedade que ele vive tenta parecer com a capitalista imposta pelos países desenvolvidos e trazem prejuízos à juventude brasileira que tenta de todas as maneiras parecer com este estilo de vida que nem de longe se parece com a do povo brasileiro, essa influência é prejudicial e faz o jovem negro acreditar na indiferença, e deixa no processo de formação marcas profundas de uma desigualdade exacerbada culminando com a violência tão explícita nos morros cariocas e nas periferias paulistanas.

Essa temática será discutida e entendida para ser colocada a disposição de futuros estudantes para elaboração de uma sociedade mais justa a partir do conhecimento desta condição que vive alguns afrodescendentes.

A história da vida privada no Brasil também é objeto de estudo que busca na memória dos afrodescendentes os acontecimentos de uma época cheia de adversidades dentro do cenário do povo negro, no memorial de ideias que está presente em todo o universo de vida e do apelo dramático vivido pelos escravos, percorre vários caminhos até chegar nos dias atuais.

A abolição da escravatura teve seu momento crucial o ano de 1888 , ocasionando entre a nobreza um grande desfalque dentro da política e da sociedade burguesa, a monarquia recebe então um grande golpe que enfraquece ainda mais o seu prestígio entre os republicanos, isso é um grande problema a ser resolvido e discutido. O que fazer com tantos negros alforriados na capital brasileira?

Essa era a pergunta que ecoava na época, diante da necessidade de resolver o problema a sociedade republicana objetivou a 
construção de uma nova condição de vida no Brasil, delimitando o espaço do negro dentro das cidades.

A maneira mais correta era inseri-los entre os demais moradores, mas isso não aconteceu. A favela é a nova senzala. Essa frase será discutida, pois o negro tão cheio de diferenças raciais e culturais foi ainda mais reduzido, a um ser sem destino.

As revoltas africanas no Brasil, realizadas por negros fugitivos, causaram um impacto na sociedade ocasionando na população temores e desconfianças. A morte de Zumbi dos Palmares e suas consequências a partir deste fato. Todos esses elementos são de fato fonte inesgotável de um estudo detalhado.

A recente luta do povo negro para se livrar do preconceito camuflado existente na sociedade de hoje, fazendo das manifestações culturais sua arma para levar aos jovens os seus argumentos de liberdade, assim eles em posse de conhecimento podem delimitar os seus caminhos. Isso deu suporte para o afrodescendente?

Essa questão pode ser respondida se a direção do barco for novamente colocada no rumo certo e decifrar os códigos implícitos dentro dessas manifestações são verdadeiramente relevantes.

A corrente que nos leva a pensar é, a priori, a mesma que movia os negros fugitivos da senzala, impulsionando sua vida para o desconhecido que era a liberdade de expressão, de manifestação, de luta social e de conquistas.

O racismo no Brasil é com certeza uma condição a ser explorada devido às consequências que elas causam e a forma com que ela está apresentada na sociedade. Ela percorre entre os negros as veias que levam ao coração, devido a forma que a mídia, os meios de comunicação apresentam à sociedade brasileira, então isso reforça a ideia que o povo afrodescendente sempre está acondicionado à falta de conhecimento científico e à ignorância.

Essa é a máxima que se vê hoje incrustada na pele dos afrodescendentes, distantes de uma realidade politicamente correta.

Permitir que as pessoas pudessem olhar para trás sem sequer entender a sua história, somente faz com que os homens e mulheres 
das nações nagôs que desterraram para o Brasil sejam comparados como seres inanimados.

Essa corrente então será examinada para que se possa deixar aberta aos que se apropriarem da métrica afrodescendente e estejam diante de um panteão de acontecimentos verdadeiros e de esclarecimentos.

As ações afirmativas já despontam com solução de uma condição imposta aos negros do Brasil e se fazem presentes nas associações que visam a aproximação das culturas e deixam para trás todo um universo de indiferenças. Ações essas que elevam a condição de povo secundário a povo igualitário nas formas mais comuns que se apresentam, sendo que as fontes de estudo devem ser esgotadas e de maneira pertinente sejam deixadas como herança cultural.

Educar o Brasil com raça, eis o grande desafio a que está sujeito todo aquele que tem como base a história verdadeira de uma nação a ser explorada, ainda assim colocadas desde o ano de 2003 com a aplicação das Diretrizes Curriculares Nacionais para a Educação das Relações Étnico-Raciais e para o Ensino de História e Cultura Afro-Brasileira e Africana, modelo que vem sendo aplicado nas escolas brasileiras de forma ainda tímida, mas, com uma perspectiva positiva diante deste milênio.

A contemporaneidade chega com milhares de desafios a serem conquistados e estão, a cada dia, mais presentes em nossa vida, a negritude aceita com normalidade os preconceitos sendo dissolvidos e a melhoria da condição social. Esses fatores são desafios a serem resolvidos dentro do contexto a ser estudado e diante de tão recente magia estabelecer parâmetros para elucidação dos entraves do cotidiano.

As culturas foram trocadas a partir da conquista da liberdade dos povos negros que estavam no Brasil, durante muito tempo os negros ficaram presos como animais que trabalhavam e não tinha valor nenhum, somente o comercial.

A resposta a tantas coisas foi esclarecida, depois de tanto tempo voltar para casa era algo impossível, mas que foi conquistado, as etnias se misturaram e, depois, deixaram suas heranças espalhadas pelo mundo. Os negros que voltaram para Benin são um exemplo 
claro disso fizeram sua história e depois foram embora. Na África fizeram da cultura brasileira uma forma clássica de se manifestar em seu país, deixando na memória sua realidade de lutas e sofrimento.

Firmadas as convenções os povos que agora são homogêneos Brasil e África destinam suas formas estéticas a compreensão dos termos que se firmaram no tempo e deixaram suas marcas, seu entendimento pode ser observado com um olhar social e temporal devido à condição que aproximou as duas nações. Suas vertentes falam do reinicio das culturas suas referências mais importantes, reflexo de duas culturas apuradas que elegeram brasileiros e africanos como essência da fusão afro-brasileira.

Refrões e simetrias deixaram de lado as suspeitas que seus descendentes são de estirpe nobres e perpassam de tempos em tempos os patamares da verdade que as duas nações agora se fundiram em uma só, dentro dos êxodos existentes entre si.

Herdeiros do tempo e das desigualdades fizeram destes dois povos o caminho inverso das Índias para contar as suas histórias e relembrar os primórdios de seus acontecimentos, são essas duas nações que relevaram a dor e o sofrimento para neste momento exaltar suas culturas.

Foram todos colocados ao vento e a sua maneira muito particular de elaborar suas culturas fazendo com que ela fosse construída dentro de um universo distorcido entre sangue e destruição.

Os retornados são em média povos que se estabeleceram nos seus países de origem depois de anos de escravidão pelo mundo e desterraram para todos os continentes e passaram por tantas atrocidades que logo após sua volta foram eleitos os retornados cheios de força e conhecimento para se destacar na sua terra.

A república do Benin é hoje uma terra conhecida pelas origens miscigenadas pelas culturas brasileiras e africanas, relacionadas pelo elo de continentes a partir de sua fusão, uma mescla que vigora até os dias atuais.

O expoente desta mescla é uma essência deixada por um homem conhecido como Francisco Félix de Souza, nascido na Bahia em 1754, filho de pai português e mãe indígena merece destaque pe- 
la valiosa contribuição destinada a cultura dos negros ocidentais na primeira metade do século XIX. Ele chegou na África por volta de 1788, tendo vivido em Uidá, Badagri e Anecho, homem de negócios que deixou sua marca entre os povos africanos do Benim.

Sua reputação crescia desde que assumiu o Forte São João Baptista da Ajuda e deteve todo o comércio de escravos da África ocidental até que foi preso pelo rei Abomé por uma disputa de dinheiro, sendo mergulhado por várias vezes em um tonel de índigo (liquido escuro) para ficar com a pele escura para parecer com um escravo, em uma maneira de se tornar inferior como eles, mas após fazer um pacto com o príncipe de Benin que também estava preso, para facilitar sua fuga conseguiu através deste pacto a derrubada do ditador beninense e a hegemonia de seu trabalho com os negros cativos.

Seu trato com o povo negro era impar, eles tinham liberdade para trabalhar e tinham suas casas, vivendo em um regime de comunidade sendo extintas as práticas de castigos com a chibata ou qualquer outro tipo de tortura, sua conduta era sem sombra de dúvidas engrandecedora, o que fazia com que os negros ficassem bem próximos dos seus senhores.

Como esta conexão entre o Brasil e a África ocidental foi feita? E como permaneceu tão forte? O livro Os Que Voltaram, de Alcione Meira Amos, conta à história dos Agudás, forma pela qual os afro-brasileiros são chamados no Benim e na Nigéria, dos Tabom como são chamados em Gana e dos afro-brasileiros do Togo alguns dos quais são chamados Nagôs.

Embora os ex-escravos brasileiros retornados tivessem origens étnicas diversas, ao chegar à África Ocidental eles se organizaram a partir da experiência comum que haviam tido no Brasil, a escravidão.

O impacto cultural dos retornados nas sociedades dos países onde se fixaram quando de volta a África foi, sem dúvida alguma, muito maior do que poderia ter sido esperado devido seu pequeno número. Na Nigéria, estabeleceram uma nova arquitetura; introduziram novas palavras no fom (uma das línguas faladas no Benim) e os descendentes dos primeiros retornados afro-brasileiros estiveram à frente da luta contra o colonialismo no Togo, muito antes que o 
chamado movimento de libertação estivesse aceso na costa ocidental da África.

Várias características permitiram que os afro-brasileiros e seus descendentes se posicionassem na alta sociedade de seus respectivos países. A principal talvez tenha sido sua dedicação para dar aos seus filhos a melhor educação possível. Assim é que, em Uidá, a escola formada pelos padres católicos era frequentada pelos filhos dos afro-brasileiros retornados, enquanto as crianças locais eram proibidas de fazer o mesmo. Outra característica que fazia deles um elemento valioso para os países recentemente libertos da colonização europeia era o conhecimento de línguas, os primeiros retornados eram pelo menos bilíngues, falando uma língua africana e o português e seus filhos continuaram com a tradição e muitos se tornaram verdadeiros poliglotas.

As influências da África que ficaram no Brasil são facilmente identificadas devido ao grau de excelência que está presente na cultura dos negros que exprime estudos e está presente dentro de cada brasileiro.

As renovações que ditam uma regra de estatísticas relevantes vêm mostrar às pessoas que existe sim uma parcela muito grande de cultura de qualidade presente nas diásporas africanas.

A língua que em primeiro plano parecia um sonido sem sentido que até se parecia com o som dos macacos fazendo um paralelo com animais irracionais que tinham apenas uma fonte de conhecimento: o trato com a natureza.

A linguagem ágrafa recém-encontrada naquelas criaturas permaneceu dentro do contexto histórico e fizeram com que as nações europeias conhecessem uma nova forma de se comunicar.

Quando dizemos que vai começar a bagunça estamos nos referindo à festa dos negros, que elevam os vocabulários bantos, presentes na nossa sociedade, o angu que está na mesa preparado com muito carinho por nossa mãe está dentro deste parâmetro diluído em partículas de conhecimento e aplicado no dia a dia das pessoas. A feijoada, o acarajé, o maxixe, o axé, o candomblé, estão presentes na língua mãe que faz referência aos primeiros homens que caminhavam pela terra. 
Um vocabulário que sempre desperta curiosidade e passa a personificar uma história. Este é o da cultura africana que ficou na boca do povo para trazer aos nossos homens e mulheres a essência da vida entre os extremos da sociedade.

As culturas africanas estão diretamente ligadas a nossa cultura brasileira, pois entre elas está a certeza da conquista da liberdade cultural e humana, sem nomear acontecimentos colocando um capítulo de dificuldades a tona seja pela dor do açoite ou pela dor da morte a parcela africana contribuiu para construir uma população etérea e contida na miscigenação dos povos. A linguagem trouxe palavras que ficaram presentes em nosso vocabulário e confirmaram as suas influências no Brasil, fecundaram nossa terra e fez do fruto uma centelha doce de sabores infinitos.

A musicalidade africana deu suporte a cultura brasileira e está espalhada pelos quatro cantos do Brasil e perpassam valores infinitos dentro do contexto da nossa cultura brasileira. Assim se faz presente nas cerimônias religiosas, no carnaval, na música popular brasileira, nos movimentos negros da Bahia e de outros estados da federação, na língua, na literatura, no teatro, no cinema entre outras manifestações.

A música vem carregada de influências africanas, pois está dentro de um horizonte de igualdade e conhecimentos que percorrem desde a elite até os mais simples brasileiros. A partir do século XVII, as notícias de bandas musicais de negros são frequentes no Brasil colônia e essa atividade vem se alastrando dentro dos anos que se seguem, para termos uma ideia ampla dos acontecimentos os negros cantavam dentro dos navios negreiros para manifestar a sua indignação à escravidão e também para manifestar a sua saudade da terra que havia sido deixado para trás devido o cativeiro. Esse canto preenchia os porões dos navios e se elevavam as brisas do mar e se perdiam pelo oceano.

Uma maneira encontrada pelos negros de se motivarem a se emanciparem dos maus tratos é que eles se manifestavam através da música e da dança, desde o amanhecer até o por do sol eles cantavam e seu canto tinha varias funções, a de amenizar a dor, a de passar mensagens aos outros negros para possíveis fugas, a de distraírem os seus donos etc. 
O samba que tem como característica a batida do tambor e também vem como manifestação dos direitos dos negros como cultura contribuinte na brasileira, no século XIX já eram vistos pelas ruas do Rio de Janeiro, os dançarinos solistas que hoje são chamados de passistas, que tinham a função de abrir o caminho nas paradas militares e religiosas dentro das suas funções ficava a de delimitar o caminho para que outros passassem, os gestos de capoeira também eram características dos que tinham a função de abrir caminho para a festa. O termo samba vem da palavra semba de origem africana e está na concepção direta da forma convencional com que os negros do Brasil celebravam sua festa.

A cultura brasileira e, logicamente, a rica música que se faz e consome no país estruturam-se a partir de duas básicas matrizes africanas, provenientes das civilizações conguesa e iorubana. A primeira sustenta as espinhas dorsais dessa música, que tem no samba sua face mais exposta. A segunda molda, principalmente, a música religiosa afrobrasileira e os estilos dela decorrentes.

(www.wikipediaculturafro.com.br)

O samba partido alto é feito através do desafio de um ou mais cantores é herança dos batuques angolanos que marcam a cadência de uma modalidade cultural de herança africana, hoje vários cantores se destacam a partir dessa influência musical que está cercada de ritmos e características provenientes da massificação dessa música e desse ritmo fazendo com que as pessoas se manifestem alegremente diante dela. Assim cantava Clara Nunes, dentro dessa linha de samba de raiz que se arrastou durante os anos setenta e oitenta, devido ao processo de libertação de Angola levando em conta toda a luta brasileira pela queda da ditadura militar que se estendia por toda a América latina. Ela conseguiu mostrar através da sua música a verdadeira influência africana, dos tambores e da sonoridade existente naquela cultura.

Essa então foi a melodia da cantora dos quilombos Clara Nunes, que dizia no canto das três raças no fragmento apresentado como referência da cultura africana na música popular brasileira.

Um canto de revolta pelos ares

Do quilombo dos palmares

Onde se refugio

Fora à luta dos inconfidentes 
Pela quebra das correntes

Nada adiantou...

Neste fragmento podemos ver que a vertente africana vem se manifestar na cultura brasileira elaborando um efeito de luta, de cantar, de dor, e de lamentação entre as três raças, distintas e presentes na constituição da sociedade brasileira.

Dentro das manifestações musicais com influências africanas além do samba vemos nos dias atuais a cultura do Rap e do Funk que exprime entre os jovens a forma mais livre de fazer música, que incorporou a sonoridade africana baseada no ritmo e na tradição oral fazendo com que sua voz chegue até aqueles que assistem as desigualdades entre a sociedade brasileira, de forma despojada e contundente, os MCs (mestres de cerimônias) fazem das suas músicas uma forma de se manifestar positivamente ou negativamente de acordo com a condição que se encontra os que estão próximos dela, fazendo da música uma arte espontânea entre os povos da periferia.

O carnaval é outra festa que tem as tradições africanas em suas raízes sendo fortemente realizada dentro dos dias atuais e se resignam para compor a história da arte do afrodescendente pelo Brasil e expor ao mundo os cantos refinados dos sambas enredos que as escolas de samba apresentam na avenida.

Segundo Roberto da Mata (1997) negros de classe média e baixa surgem também como corporações nos seus clubes cujos nomes são significativos, fazendo uma alusão ao destaque que dá ao negro o carnaval e a sua concepção.

As culturas foram trocadas e fizeram bem a cada uma das nações e durante todos esses anos contribuíram para serem construídas novas fontes de sabedoria, renovadas a cada instante, a criatividade que cercava cada uma das nações fez com que fosse construída uma muralha de igualdade vinda dos dois povos.

Esses povos fizeram da sua história uma vertente de verdade e soberania deixando no mundo a certeza de que povos negros e miscigenados podem ser fortes diante da indiferença dos povos. 


\section{REFERÊNCIAS}

CAMARGO, Oswaldo de. O negro escrito. Apontamentos sobre a presença do negro na literatura brasileira. Imprensa oficial do estado S/A IMESP, 1987.

CUNHA, Manuela Carneiro da. Negros estrangeiros. Dos escravos libertos e sua volta à África. Brasiliense, 1975.

DA MATTA, Roberto. Carnavais, malandros e heróis: para uma sociedade do dilema brasileiro. 6. ed. Rio de Janeiro: Rocco, 1997.

DIRETRIZES Curriculares Nacionais para a Educação das relações étnico-raciais e para o ensino de história e cultura afro-brasileira e africana. Brasília, 2005.

FREYRE, Gilberto. Problemas brasileiros de antropologia. Pref. do Prof. Gonçalves Fernandes. $4^{a}$ ed. Rio de Janeiro: José Olympio; Instituto Nacional do Livro, 1973.

GUIMARÃES, Antonio Sergio Alfredo. Classes, raças e democracia [democracia]. São Paulo: Universidade de São Paulo; Editora 34, 2002.

GURAN, Milton. Agudás: os brasileiros do Benim. Rio de Janeiro: Nova Fronteira 2000.

http://blig.ig.com.br/jonlinesenac/2008/10/01/sincretismo-religiosouma-associacao-entre-as-religioes-africanas-e-o-catolicismo. Disponível em 30/05/09.

http://conversademenina.wordpress.com/2009/02/22/africaresistencia-carnaval. Disponível em 29-03-09.

http://expressaodeideias.blogspot.com/2007/05/critica-religiohumana-2.html. Disponível em 21/05/09

http://pt.wikipedia.org/wiki/Cultura_afro-brasileira. Disponível em 29/03/09.

http://pt.wikipedia.org/wiki/Religi\%C3\%B5es_no_Brasil. Disponível em 30/05/09.

RAMOS, Artur. As culturas negras no mundo novo. 3. ed. São Paulo: Cia. Ed. Nacional; [Brasília]: INL, 1979. 


\section{FACULDADE de FoRMAÇÃO de PROFESSORES}

SANTOS, Gislene Aparecida dos. A invenção do ser negro: um percurso das ideias que naturalizam a inferioridade dos negros. 1. ed. São Paulo: Educ/Fapesp; Rio de Janeiro: Pallas, 2006.

SANTOS, Ivair Augusto dos. O movimento negro e o estado (1983 1987): O caso do conselho de participação e desenvolvimento da comunidade negra no governo e São Paulo, 2001.

VENTURA, Nancy Caruso. Negro: Reconstruindo nossa história. Ilustrações Jefferson Galdino, Nireuda Longobardi. São Paulo: Noovha América, 2003. 